\title{
MultipLa - a tool for the combined overall estimation of various types of manual handling tasks
}

\author{
Schaub Karlheinz ${ }^{\mathrm{a}}$, Steinberg Ulf ${ }^{\mathrm{b}}$, Bierwirth Max ${ }^{\mathrm{a}}$, Kugler Michaela ${ }^{\mathrm{a}}$, and Bruder Ralph ${ }^{\mathrm{a}}$ \\ a Institute of Ergonomics, Darmstadt University of Technology, Petersenstr. 30, D-64287 D-64287 Darmstadt, \\ Germany. Corresponding author: Karlheinz Schaub; Phone: +49 (0) 6151 16 3489; Fax: +49 (0) 6151163488 ; \\ Schaub@iad.tu-darmstadt.de \\ ${ }^{\mathrm{b}}$ German National Institute of Occupational Health and Safety, Noeldnerstr. 40-42, D-10317 Berlin, Germany
}

\begin{abstract}
In the 1990ies the German Federal Institute for Occupational Safety and Health (FIOSH) published "Key Indicator Methods" (KIM) for the evaluation of manual material handling tasks. These methods served as a national German implementation of the EU Manual Handling Directive (90/269/EEC). These methods allow the evaluation of individual handling tasks like lifting or pushing. KIM tools do not allow evaluating complex handling tasks like a combined lifting and pushing task. With respect to the needs at shop floor level (e.g. logistics), MultipLa tries to bridge that gap by means of an EXCEL based worksheet using the KIM philosophy. In the past several algorithms for a risk assessment had been developed. At the moment MultipLa is in a test phase at several automotive OEMs.
\end{abstract}

Keywords: Risk assessment, manual materials handling, key indicator method, complex handling tasks

\section{Introduction}

Musculoskeletal disorders play an import role in industries and are responsible for more than one third of the total sick leave [1]. Besides this they generate high costs for companies and national economies. In Germany 2006, MSDs generated a loss of more than 400 million working days and a productivity loss of about 36 billion $€[1]$.

Manual materials handling (MMH) is one of the most common physically demanding activities. Low back pain and subsequent diseases are common in industrialized countries and lead in Europe to the EU-Directive on manual materials handling 90/269/EEC [2]).

In general in Europe the protection of health \& safety at work is regarded as a public responsibility. The common European system of health and safety at work is mainly set up by the EU-Machinery Directive (2006/42/EC [3]) and EU-Framework Directive (89/391/EEC [4], including relevant Individual Directives, which demand ergonomic risk assessments to be carried out in various phases of the product life cycle.

As MMH activities are quite common all over the world various methods for their evaluation had been created.

In the 1970ies a method for the calculation of mass limits was created at the ergonomic labs at Siemens and was later on published by Burandt [5]. It became the source of diverse other methods and had gained the quality of a "quasi standard" in Germany.

In the U.S. the NIOSH work practices guide was published in 1981 and replaced by a revised NIOSH lifting equation [5].

Different from the NIOSH uni-sex and uni-age approach the Siemens methodology considered the influences of the gender and the age. Both the NIOSH as well as the Siemens method left some footprints when EN 1005-2 [7] and ISO 11228-1 [8] had been realized. As a second level analysis tool both methods were not able to serve as a quick first level screening tool. 
This bridge was gapped by the Key Indicator Method (KIM) on manual materials handling (repositioning, holding and carrying [8], followed by a method for the evaluation of pushing and pulling tasks), which had been created by the German FIOSH's (Federal Institute of Occupational Safety \& Health) as a national German implementation of the EU manual handling Directive.

\section{Methods}

The KIM method considers primarily the key items time (frequency of operation for lifting and short distance pushing or holding time or distance for carrying or long distance pushing \& pulling), mass, gender, working posture and work station related conditions of handling activities.

The tool operates on a 3 step level:

1. assessment of time aspects

2. assessment of key items

3. risk assessment

In general KIM assigns points for the various key items, where as the higher the points the higher the load. Table 1 gives an example of "time points" granted to the frequency of repositioning operations per shift.

Once the key items have been derived a risk score is calculated as shown in table 2 .

Table 1

Time points $\mathrm{f}_{\text {time }}$ for the number of repositionings of loads per shift

\begin{tabular}{|l|l|}
\hline Repetitive lifting or manipulation of loads & $\mathrm{f}_{\text {time }}$ \\
\hline$<10$ times per shift & 1 \\
\hline 10 to 40 times per shift & 2 \\
\hline 40 to 200 times per shift & 4 \\
\hline 200 to 500 times per shift & 6 \\
\hline 500 to 1000 times per shift & 8 \\
\hline$\geq 1000$ times per shift & 10 \\
\hline
\end{tabular}

Table 2

Calculation of risk score from key items load, posture, condition and time

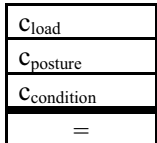

$\mathrm{X}$
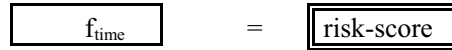

Dependant on the risk score a risk zone is associated to the task as shown in table 3 .
Generally it is assumed, that the risk of overloading the musculoskeletal system increases, while the risk scores increase. Due to individual working techniques and physical capabilities, there are no sharp borderlines between the risk zones. The risk assessment should be regarded as guidance. More detailed analysis requires ergonomic background knowledge.

Table 3

Definition of risk zones dependant on the risk score

\begin{tabular}{|l|l|l|}
\hline $\begin{array}{l}\text { risk } \\
\text { zone }\end{array}$ & risk-score & description \\
\hline 1 & $<10$ & $\begin{array}{l}\text { low load situation, hazardous situations due } \\
\text { to physical overload are unlikely to appear. }\end{array}$ \\
\hline 2 & $10<25$ & $\begin{array}{l}\text { increased load situation, an overload situation } \\
\text { is possible for less resilient persons. For that } \\
\text { group workplace redesign is helpful. }\end{array}$ \\
\hline 3 & $25<50$ & $\begin{array}{l}\text { highly increased load situation, physical } \\
\text { overload is possible, even for ,normal“ per- } \\
\text { sons. Workplace redesign is recommended. }\end{array}$ \\
\hline 4 & $\geq 50$ & $\begin{array}{l}\text { High load situation, physical overload is } \\
\text { likely to appear. Workplace redesign is an } \\
\text { urgent matter. }\end{array}$ \\
\hline
\end{tabular}

Less resilient persons in this context are: persons older than 40 or younger than 21 , ,newcomer" in the job, or people suffering from illness.

Design requirements may be derived by means of the score in the key item tables. By lowering the loads, improving the posture and working conditions, or reducing the time under load, increased strain may be avoided.

\section{Implementation / case studies}

Like the NIOSH or the Siemens method the key item method allows the evaluation of one type of handling (e.g. lifting OR pushing) only.

Of course it is possible to just add the scores of individual risk assessments for different type of handling tasks. Like the NIOSH the key element method is based on a psychophysical, physiological and biomechanical approach. With respect to the psychophysical approach the time scale of the key item method is not linear, but digressive [10], as it also applies to the data of Snook \& Ciriello [11].

Combining different types of MMH activities by just adding the scores of the analysis carried out will be substantially misleading and generate too high scores as the steep increase of the time score is considered multiply.

The basic idea of MultipLa is therefore to have a unique time axis for all types of different $\mathrm{MMH}$ activities. Times or distances for holding, carrying, 
pushing and pulling are therefore converted to repositioning equivalents and finally redistributed according to their percentage of distribution of all $\mathrm{MMH}$ activities.

For the combination of multiple types of $\mathrm{MMH}$ tasks as well as for the calculation of multiple tasks within one type of MMH tasks, two models have been implemented. One model is close to the NIOSH 1981 multiple task method; i.e. all frequencies of the tasks are added and for the load level a frequency weighted mass is calculated.

The second average approach is similar to the NIOSH 91 multiple approach. It considers the most severe case with the original frequency where as the subsequent tasks are considered with their relevant time multiplier.

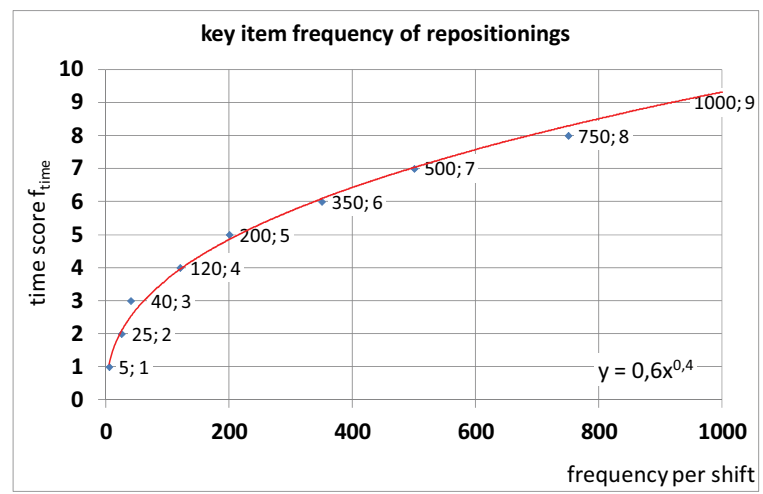

Fig. 1 Company internal ergonomic process considering the company's structure and EU legal requirements; risk assessment tools serve as a common platform

\section{Discussion}

MultipLa was a first approach to develop a screening tool for the evaluation of multiple and mixed $\mathrm{MMH}$ activities. As described in the last paragraph a set of algorithms has been developed to calculate an overall risk estimation. If many different types of MMH activities occur, the outcome of a risk assessment might be interpreted quite well from a physiological point of view. However single load peeks in terms of a biomechanical overload might be middle out. Therefore an algorithm has been implemented that highlights possible biomechanical overloads. Whenever a combination of posture and load scores are considered to exceed the "Dortmunder Richtwerte" for a lumbar spine compression for a 40 year old male operator, the respective line is highlighted. So besides a physiological bottleneck also a biomechanical one is discovered.

Currently a field test with the various MultipLa algorithms is going on at several automotive OEMs in Germany.

\section{References}

[1] Elke Schneider and Xabier Irastorza, Work-related musculoskeletal disorders in the EU — Facts and figures, European Agency for Safety and Health at Work, 2010, ISBN 978-929191-261-2,

http://osha.europa.eu/en/publications/reports/TERO09009EN C/view? searchterm $=$ None

[2] Council Directive 90/269/EEC of 29 May 1990 on the minimum health and safety requirements for the manual handling of loads where there is a risk particularly of back injury to workers (fourth individual Directive within the meaning of Article 16 (1) of Directive 89/391/EEC), Official Journal of the European Union, No. L 156/9, 21.6.1990

[3] DIRECTIVE 2006/42/EC OF THE EUROPEAN PARLIAMENT AND OF THE COUNCIL of 17 May 2006 on machinery, and amending Directive 95/16/EC (recast), Official Journal of the European Union, L 157/24, 9.6.2006 http://eur-

lex.europa.eu/LexUriServ/LexUriServ.do?uri=OJ:L:2006:157: 0024:0086:EN:PDF

[4] Council Directive 89/391/EEC of 12 June 1989 on the introduction of measures to encourage improvements in the safety and health of workers at work, Official Journal of the European Union, No. L 183/1, 29.6.1998

[5] Burandt, U.: Ergonomie für Design und Entwicklung. Köln O. Schmidt, 1978

[6] Waters, T.R., Putz-Anderson, V., Garg, A., Fine, L.J., 1993 Revised NIOSH equation for the design and evaluation of manual lifting tasks. Ergonomics 36 (7), 749-776.

[7] EN 1005-2 Safety of machinery. Human physical performance. Part 2. Manual handling of machinery and component parts of machinery

[8] ISO 11228-1 System of standards for labor safety. Ergonomics. Manual handling. Part 1. Lifting and carrying. General requirements

[9] Steinberg, U.; Caffier, G.; Liebers, F.: Assessment of Manual Material Handling based on Key Indicators - German Guidelines. In: Handbook of Standards in Ergonomics and Human Factors. Ed. by W. Karwowski. Lawrenz Erlbaum Associates. Mahwah, New Jersey, London 2006. S. 319-338. ISBN 08058-4129-6

[10] Schaub, Karlheinz ; Haßß, Prisca ; Bierwirth, Max ; Kugler, Michaela ; Steinberg, Ulf ; Kaltbeitzel, Jürgen ; Toledo, Begoña ; Bruder, Ralph : Das Multiple-Lasten-Tool: integrierte Bewertung unterschiedlicher Arten manueller Lastenhandhabung. In: Mensch- und prozessorientierte Arbeitsgestaltung im Fahrzeugbau, Herbstkonferenz 2010 der Gesellschaft für Arbeitswissenschaft, 23. - 24. September 2010, Wolfsburg. GfA Press , Dortmund

[11] Snook, S. H. and Ciriello, V. M.; The design of manual handling tasks: revised tables of maximum acceptable weights and forces, Ergonomics, 34:9 1197-1213, 1991. 